\title{
Популяционная изменчивость содержания микро- и макроэлементов в органах Lonicera caerulea subsp. altaica (Горный Алтай, Северо-Чуйский хр., р. Кызыл-Ярык)
}

\section{Population variability of micro and macro content in the organs of Lonicera caerulea subsp. altaica (Gorny Altai, Severo-Chuisky Range, Kyzyl-Yaryk River)}

\author{
Волкова Л. Р. ${ }^{1}$, Боярских И. Г. ${ }^{1,2}$, Сиромля Т. И. ${ }^{2}$ \\ Volkova L. R. ${ }^{1}$, Boyarskikh I. G. ${ }^{1,2}$, Siromlya T. I. ${ }^{2}$ \\ ${ }^{I}$ Центральный сибирский ботанический сад СО РАН, г. Новосибирск, Россия. \\ E-mails:97lyudmila-volk@mail.ru,irina_2302@mail.ru \\ ${ }^{2}$ Институт почвоведения и агрохимии СО РАH, г.Новосибирск, Россия._E-mail: tatiana@issa.nsc.ru, irina_2302@mail.ru \\ ${ }^{1}$ Central Siberian Botanical Garden of the SB RAS, Novosibirsk, Russia \\ ${ }^{2}$ Institute of Soil Science and Agrochemistry of SB RAS, Novosibirsk, Russia
}

Peфepam. Проведен сравнительный анализ содержания микро- и макроэлементов в плодах, листьях и стеблях Lonicera caerulea subsp. altaica в природной популяции в долине р. Кызыл-Ярык (Северо-Чуйский хр., Горный Алтай) в локальной зоне сгущенния дизъюнктивных геологических структур.

Ключевые слова. Горный Алтай, листья, макро- и микроэлементы, плоды, стебли, Lonicera caerulea subsp. altaica.

Summary. The article shows the results of comparative analysis of the content of micro and macro elements in the fruits, leaves and stems of Lonicera caerulea subsp. altaica in the natural population in the valley of the river KyzylYaryk (Severo-Chuisky Range, the Altai Mountains) in the zone of thickening of disjunctive geological structures.

Key words. The Altai Mountains, fruits, leaves, Lonicera caerulea subsp. altaica, macro- and microelements.

Жимолость синяя Lonicera caerulea L. - важное ресурсное растение, которое имеет большую ценность. Она обусловлена сверхранним сроком созреванием плодов, высоким содержанием в них витамина С, биологически активных фенольных соединений, (Chaovanalikit et al., 2004; Стрельцина и др., 2006), микро-и макроэлементов проявляющих антиоксидантную, иммуномодулирующую, антибактериальную, противовирусную, противогрибковую, антиаллергическую и др. виды активности (Jurikova et al., 2012). Целебные свойства L. caerulea известны очень давно. В традиционной, в том числе и тибетской медицине, для лечения различных заболеваний применяют не только плоды, но и листья, цветки, кору и ветви L. caerulea (Минаева, 1991).

На территории Горного Алтая L. caerulea произрастает в разнообразных экологических условиях, на разных высотах бореального вертикального пояса и склонах различной экспозиции, при неодинаковой величине инсоляции, тепло- и влагообеспеченности местообитаний. Популяции L. caerulea располагаются на участках, сложенных разнообразными горными породами, нередко с рудопроявлениями, в зонах сгущенных дизъюнктивных геологических структур и активных тектонических процессов, способных оказывать влияние на химизм почв, почвенных вод, почвенного и приземного воздуха, а также биохимический состав растений.

Целью данной работы было изучение видовой специфичности содержания и распределения макро- и микроэлементов в вегетативных и генеративных органах L. caerulea subsp. altaica Pall. (Caprifoliaceae Juss.), а также диапазона варьирования их концентраций в популяции Горного Алтая в 
долине р. Кызыл-Ярык. Исследования проводили в 2017 г. на участке Северо-Чуйского хребта Горного Алтая. Участок проведения исследований был выбран в узле сочленения разломов на границе Северо-Чуйского хребта и Курайской межгорной впадины с разломной границей Чаган-Узунского горста, разделяющего Курайскую и Чуйскую впадины, в долине р. Кызыл-Ярык (Agatova, Nepop, 2016). Для изучения содержания микро- и макроэлементов в органах растений использовался метод атомно-эмиссионной спектрометрии.

Объектами исследования служили листья, стебли и плоды L. caerulea, собранные в фазе созревания плодов.

Анализ содержания 27 изученных микро- и макроэлементов в листьях, плодах и стеблях L. caerulea subsp. altaica показал различный характер распределения и накопления микро- и макроэлементов в органах жимолости синей (табл. 1). Макроэлементы: $\mathrm{Ca}, \mathrm{Mg}, \mathrm{K}, \mathrm{P}, \mathrm{Si}, \mathrm{Fe}, \mathrm{Na}$ и микроэлементы: $\mathrm{Cu}, \mathrm{Co}, \mathrm{Cr}, \mathrm{Mn}, \mathrm{Zn}, \mathrm{V}, \mathrm{Ni}, \mathrm{Mo}, \mathrm{Ba}, \mathrm{B}, \mathrm{Sr}$-относятся к биофильным (эссенциальным) элементам. Биологическое значение других химических элементов, обнаруженных в органах L. caerulea subsp. altaica, пока еще недостаточно ясно.

Таблица 1

Содержание элементов в органах L. caerulea subsp. altaica в долине р. Кызыл-Ярык (мг/кг воздушно-сухого вещества; $\mathrm{K}, \mathrm{Ca}, \mathrm{Mg}-$ г/кг)

\begin{tabular}{|c|c|c|c|c|c|c|}
\hline & & $\begin{array}{c}\text { Кызыл - Ярык } \\
1\end{array}$ & $\begin{array}{c}\text { Кызыл - Ярык } \\
2\end{array}$ & $\begin{array}{c}\text { Кызыл - Ярык } \\
3\end{array}$ & $\begin{array}{c}\text { Кызыл - Ярык } \\
4\end{array}$ & $\begin{array}{c}\text { Кызыл - Ярык } \\
5\end{array}$ \\
\hline \multirow{3}{*}{$\begin{array}{c}\text { зола, } \\
\%\end{array}$} & листья & $9,4 \pm 0,1$ & $9,2 \pm 0,2$ & $9,5 \pm 0,1$ & $8,2 \pm 0,55$ & $6,9 \pm 0,1$ \\
\hline & плоды & $4,4 \pm 0,2$ & $4,8 \pm 0,2$ & $4,8 \pm 0,2$ & $6,3 \pm 0,71$ & $3,4 \pm 0,3$ \\
\hline & стебель & $3,6 \pm 0,1$ & $3,8 \pm 0,1$ & $3,4 \pm 0,1$ & $3,5 \pm 0,2$ & $2,2 \pm 0,1$ \\
\hline \multirow{3}{*}{$\mathrm{Al}$} & листья & $58 \pm 2$ & $60 \pm 4$ & $54 \pm 2$ & $61 \pm 9$ & $51 \pm 3$ \\
\hline & плоды & $20 \pm 0,9$ & $20 \pm 1,3$ & $17 \pm 0,9$ & $30 \pm 9,8$ & $12 \pm 0,7$ \\
\hline & стебель & $82 \pm 5$ & $75 \pm 10$ & $83 \pm 13$ & $72 \pm 8$ & $65 \pm 3$ \\
\hline \multirow{3}{*}{ B } & листья & $38 \pm 2,8$ & $40 \pm 1,4$ & $35 \pm 1,4$ & $34 \pm 4,1$ & $29 \pm 1,0$ \\
\hline & плоды & $12 \pm 0,7$ & $12 \pm 0,4$ & $11 \pm 0,4$ & $18 \pm 4,4$ & $8,1 \pm 0,8$ \\
\hline & стебель & $12 \pm 0,4$ & $15 \pm 0,6$ & $13 \pm 0,8$ & $12 \pm 0,7$ & $8,5 \pm 0,4$ \\
\hline \multirow{3}{*}{$\mathrm{Ba}$} & листья & $74 \pm 3$ & $118 \pm 11$ & $124 \pm 6,7$ & $103 \pm 17$ & $82 \pm 3,3$ \\
\hline & плоды & $11 \pm 0,6$ & $16 \pm 1,2$ & $17 \pm 1,3$ & $33 \pm 15$ & $9,4 \pm 0,7$ \\
\hline & стебель & $55 \pm 3,5$ & $105 \pm 12$ & $85 \pm 5,5$ & $69 \pm 3,7$ & $51 \pm 4,9$ \\
\hline \multirow{3}{*}{$\mathrm{Be}$} & листья & $0,1 \pm 0,004$ & $0,1 \pm 0,003$ & $0,1 \pm 0,003$ & $0,05 \pm 0,004$ & $0,04 \pm 0,002$ \\
\hline & плоды & $0,03 \pm 0,002$ & $0,03 \pm 0,002$ & $0,02 \pm 0,001$ & $0,04 \pm 0,004$ & $0,02 \pm 0,003$ \\
\hline & стебель & $0,03 \pm 0,002$ & $0,03 \pm 0,001$ & $0,02 \pm 0,001$ & $0,02 \pm 0,002$ & $0,01 \pm 0,001$ \\
\hline \multirow{3}{*}{$\mathrm{Ca}$} & листья & $21 \pm 0,7$ & $18 \pm 0,4$ & $18 \pm 0,8$ & $16 \pm 2,7$ & $14 \pm 0,6$ \\
\hline & плоды & $2,7 \pm 0,3$ & $2,8 \pm 0,1$ & $3,0 \pm 0,2$ & $5,6 \pm 2,6$ & $1,8 \pm 0,3$ \\
\hline & стебель & $6,4 \pm 0,2$ & $6,8 \pm 0,3$ & $5,4 \pm 0,2$ & $5,5 \pm 0,3$ & $3,5 \pm 0,1$ \\
\hline \multirow{3}{*}{$\mathrm{Ce}$} & листья & $1,5 \pm 0,1$ & $1,4 \pm 0,1$ & $1,4 \pm 0,04$ & $1,3 \pm 0,11$ & $2,2 \pm 0,2$ \\
\hline & плоды & $0,8 \pm 0,1$ & $0,8 \pm 0,1$ & $0,8 \pm 0,04$ & $1,04 \pm 0,14$ & $1,1 \pm 0,2$ \\
\hline & стебель & $0,6 \pm 0,02$ & $0,8 \pm 0,1$ & $0,7 \pm 0,1$ & $0,5 \pm 0,04$ & $0,7 \pm 0,1$ \\
\hline \multirow{3}{*}{ Co } & листья & $0,1 \pm 0,02$ & $0,1 \pm 0,02$ & $0,2 \pm 0,01$ & $0,1 \pm 0,01$ & $0,2 \pm 0,03$ \\
\hline & плоды & $0,1 \pm 0,01$ & $0,1 \pm 0,01$ & $0,1 \pm 0,01$ & $0,1 \pm 0,01$ & $0,1 \pm 0,04$ \\
\hline & стебель & $0,03 \pm 0,004$ & $0,1 \pm 0,02$ & $0,1 \pm 0,01$ & $0,1 \pm 0,01$ & $0,1 \pm 0,01$ \\
\hline \multirow{3}{*}{$\mathrm{Cr}$} & листья & $0,7 \pm 0,1$ & $0,6 \pm 0,03$ & $0,4 \pm 0,01$ & $0,4 \pm 0,04$ & $0,3 \pm 0,01$ \\
\hline & плоды & $0,2 \pm 0,01$ & $0,2 \pm 0,01$ & $0,2 \pm 0,02$ & $0,3 \pm 0,04$ & $0,1 \pm 0,02$ \\
\hline & стебель & $0,3 \pm 0,02$ & $0,4 \pm 0,02$ & $0,3 \pm 0,02$ & $0,2 \pm 0,02$ & $0,2 \pm 0,02$ \\
\hline \multirow{3}{*}{$\mathrm{Cu}$} & листья & $12 \pm 0,7$ & $13 \pm 0,7$ & $11 \pm 0,6$ & $9,4 \pm 0,7$ & $4,6 \pm 0,9$ \\
\hline & плоды & $13 \pm 1,4$ & $13 \pm 0,4$ & $15 \pm 1,3$ & $12 \pm 0,6$ & $3,8 \pm 0,4$ \\
\hline & стебель & $10 \pm 1,4$ & $15 \pm 0,7$ & $13 \pm 0,4$ & $11 \pm 1,9$ & $3,1 \pm 0,5$ \\
\hline
\end{tabular}


«Проблемы ботаники Южной Сибири и Монголии» - XVIII Международная научно-практическая конференция

Таблица 1 (продолжение)

\begin{tabular}{|c|c|c|c|c|c|c|}
\hline & & $\begin{array}{c}\text { Кызыл - Ярык } \\
1\end{array}$ & $\begin{array}{c}\text { Кызыл - Ярык } \\
2\end{array}$ & $\begin{array}{c}\text { Кызыл - Ярык } \\
3\end{array}$ & $\begin{array}{c}\text { Кызыл - Ярык } \\
4\end{array}$ & $\begin{array}{c}\text { Кызыл - Ярык } \\
5\end{array}$ \\
\hline \multirow{3}{*}{$\mathrm{Fe}$} & листья & $67 \pm 5,9$ & $67 \pm 1,1$ & $46 \pm 2,6$ & $68 \pm 8,9$ & $43 \pm 4,3$ \\
\hline & плоды & $20 \pm 2,2$ & $19 \pm 1,2$ & $19 \pm 1,6$ & $36 \pm 10$ & $12 \pm 2,3$ \\
\hline & стебель & $65 \pm 4,7$ & $53 \pm 5,2$ & $58 \pm 10,2$ & $59 \pm 5,4$ & $45 \pm 4,2$ \\
\hline \multirow{3}{*}{$\mathrm{Ga}$} & листья & $0,3 \pm 0,03$ & $0,3 \pm 0,02$ & $0,3 \pm 0,01$ & $0,2 \pm 0,01$ & $0,1 \pm 0,01$ \\
\hline & плоды & $0,2 \pm 0,01$ & $0,1 \pm 0,01$ & $0,1 \pm 0,01$ & $0,2 \pm 0,02$ & $0,1 \pm 0,01$ \\
\hline & стебель & $0,1 \pm 0,01$ & $0,1 \pm 0,01$ & $0,1 \pm 0,01$ & $0,1 \pm 0,01$ & $0,04 \pm 0,002$ \\
\hline \multirow{3}{*}{$\mathrm{K}$} & листья & $17 \pm 1,01$ & $16 \pm 1,04$ & $14 \pm 0,7$ & $17 \pm 2,1$ & $9,2 \pm 0,8$ \\
\hline & плоды & $15 \pm 1,4$ & $18 \pm 0,4$ & $19 \pm 0,7$ & $22 \pm 0,8$ & $12 \pm 1,4$ \\
\hline & стебель & $7,9 \pm 0,4$ & $8,5 \pm 0,3$ & $7,4 \pm 0,3$ & $8,3 \pm 0,3$ & $4,6 \pm 0,5$ \\
\hline \multirow{3}{*}{$\mathrm{La}$} & листья & $0,3 \pm 0,02$ & $0,4 \pm 0,02$ & $0,4 \pm 0,02$ & $0,4 \pm 0,04$ & $0,3 \pm 0,04$ \\
\hline & плоды & $0,2 \pm 0,01$ & $0,2 \pm 0,02$ & $0,2 \pm 0,01$ & $0,3 \pm 0,04$ & $0,2 \pm 0,1$ \\
\hline & стебель & $0,1 \pm 0,02$ & $0,2 \pm 0,1$ & $0,2 \pm 0,02$ & $0,1 \pm 0,01$ & $0,1 \pm 0,01$ \\
\hline \multirow{3}{*}{$\mathrm{Mg}$} & листья & $3,5 \pm 0,1$ & $3,9 \pm 0,1$ & $3,6 \pm 0,2$ & $3,6 \pm 0,4$ & $2,9 \pm 0,1$ \\
\hline & плоды & $0,9 \pm 0,02$ & $1,1 \pm 0,04$ & $0,9 \pm 0,1$ & $0,9 \pm 0,1$ & $0,6 \pm 0,03$ \\
\hline & стебель & $0,1 \pm 0,1$ & $1,2 \pm 0,04$ & $1,2 \pm 0,1$ & $1,8 \pm 0,5$ & $0,8 \pm 0,1$ \\
\hline \multirow{3}{*}{$\mathrm{Mn}$} & листья & $54 \pm 4,4$ & $53 \pm 6,3$ & $35 \pm 1,4$ & $79 \pm 14,3$ & $98 \pm 20$ \\
\hline & плоды & $16 \pm 1,4$ & $16 \pm 0,6$ & $12 \pm 0,9$ & $34 \pm 12$ & $16 \pm 2,9$ \\
\hline & стебель & $91 \pm 4,2$ & $114 \pm 17$ & $87 \pm 9,2$ & $94 \pm 15$ & $127 \pm 15$ \\
\hline \multirow{3}{*}{ Mo } & листья & $3,9 \pm 0,8$ & $1,7 \pm 0,14$ & $0,9 \pm 0,1$ & $0,1 \pm 0,01$ & $0,1 \pm 0,01$ \\
\hline & плоды & $0,5 \pm 0,1$ & $0,3 \pm 0,03$ & $0,1 \pm 0,01$ & $0,1 \pm 0,01$ & $0,03 \pm 0,01$ \\
\hline & стебель & $0,2 \pm 0,03$ & $0,2 \pm 0,02$ & $0,1 \pm 0,02$ & $0,1 \pm 0,02$ & $0,02 \pm 0,003$ \\
\hline \multirow{3}{*}{$\mathrm{Na}$} & листья & $67 \pm 3,4$ & $79 \pm 4,3$ & $76 \pm 0,9$ & $72 \pm 3,8$ & $47 \pm 2,3$ \\
\hline & плоды & $33 \pm 1,3$ & $34 \pm 2,8$ & $33 \pm 1,8$ & $52 \pm 5,1$ & $24 \pm 2,1$ \\
\hline & стебель & 351,7 & $36 \pm 1,4$ & $42 \pm 3,8$ & $42 \pm 1,8$ & $25 \pm 1,4$ \\
\hline \multirow{3}{*}{$\mathrm{Ni}$} & листья & $1,4 \pm 0,1$ & $1,69 \pm 0,1$ & $1,2 \pm 0,03$ & $1,4 \pm 0,2$ & $0,7 \pm 0,04$ \\
\hline & плоды & $1,4 \pm 0,2$ & $2,1 \pm 0,1$ & $1,7 \pm 0,1$ & $1,6 \pm 0,2$ & $1,1 \pm 0,25$ \\
\hline & стебель & $0,5 \pm 0,04$ & $0,9 \pm 0,1$ & $0,7 \pm 0,1$ & $0,9 \pm 0,3$ & $0,5 \pm 0,05$ \\
\hline \multirow{3}{*}{$\mathrm{P}$} & листья & $4065 \pm 302$ & $4031 \pm 310$ & $2065 \pm 161$ & $2683 \pm 173$ & $1657 \pm 211$ \\
\hline & плоды & $2133 \pm 88$ & $2275 \pm 85$ & $1746 \pm 112$ & $2324 \pm 53$ & $1142 \pm 108$ \\
\hline & стебель & $798 \pm 51$ & $1109 \pm 37$ & $783 \pm 79$ & $691 \pm 32$ & $435 \pm 38$ \\
\hline \multirow{3}{*}{$\mathrm{Pb}$} & листья & $0,6 \pm 0,1$ & $0,6 \pm 0,03$ & $0,5 \pm 0,02$ & $0,5 \pm 0,1$ & $0,3 \pm 0,02$ \\
\hline & плоды & $0,3 \pm 0,03$ & $0,3 \pm 0,01$ & $0,2 \pm 0,01$ & $0,3 \pm 0,1$ & $0,1 \pm 0,03$ \\
\hline & стебель & $0,4 \pm 0,03$ & $0,4 \pm 0,03$ & $0,4 \pm 0,07$ & $0,3 \pm 0,04$ & $0,2 \pm 0,02$ \\
\hline \multirow{3}{*}{$\mathrm{Sc}$} & листья & $0,1 \pm 0,01$ & $0,1 \pm 0,01$ & $0,1 \pm 0,004$ & $0,1 \pm 0,01$ & $0,03 \pm 0,01$ \\
\hline & плоды & $0,03 \pm 0,004$ & $0,04 \pm 0,004$ & $0,02 \pm 0,01$ & $0,03 \pm 0,01$ & $0,02 \pm 0,01$ \\
\hline & стебель & $0,03 \pm 0,01$ & $0,04 \pm 0,01$ & $0,04 \pm 0,01$ & $0,02 \pm 0,001$ & $0,02 \pm 0,004$ \\
\hline \multirow{3}{*}{$\mathrm{Si}$} & листья & $1631 \pm 214$ & $1796 \pm 210$ & $758 \pm 22$ & $727 \pm 140$ & $583 \pm 87$ \\
\hline & плоды & $69 \pm 5,7$ & $73 \pm 8,6$ & $64 \pm 3,5$ & $236 \pm 124$ & $40 \pm 4,1$ \\
\hline & стебель & $242 \pm 17$ & $209 \pm 24$ & $250 \pm 38$ & $177 \pm 21$ & $142 \pm 15$ \\
\hline \multirow{3}{*}{$\mathrm{Sr}$} & листья & $151 \pm 5,5$ & $145 \pm 3,9$ & $97 \pm 8,6$ & $80 \pm 15$ & $67 \pm 3,2$ \\
\hline & плоды & $23 \pm 2$ & $24 \pm 1$ & $13 \pm 1$ & $24 \pm 1$ & $7 \pm 1$ \\
\hline & стебель & $64 \pm 4$ & $80 \pm 3$ & $43 \pm 2$ & $38 \pm 3$ & $27 \pm 1$ \\
\hline \multirow{3}{*}{$\mathrm{Ti}$} & листья & $3,1 \pm 0,2$ & $2,9 \pm 0,31$ & $2,7 \pm 0,1$ & $3,8 \pm 0,6$ & $2,7 \pm 0,1$ \\
\hline & плоды & $0,8 \pm 0,1$ & $0,9 \pm 0,09$ & $0,9 \pm 0,1$ & $1,7 \pm 0,6$ & $0,8 \pm 0,1$ \\
\hline & стебель & $5,8 \pm 0,5$ & $4,5 \pm 0,75$ & $5,5 \pm 1,0$ & $4,9 \pm 0,7$ & $3,7 \pm 0,5$ \\
\hline \multirow{3}{*}{$\mathrm{V}$} & листья & $0,5 \pm 0,01$ & $0,5 \pm 0,02$ & $0,5 \pm 0,01$ & $0,5 \pm 0,04$ & $0,4 \pm 0,01$ \\
\hline & плоды & $0,2 \pm 0,01$ & $0,3 \pm 0,01$ & $0,2 \pm 0,01$ & $0,3 \pm 0,1$ & $0,2 \pm 0,02$ \\
\hline & стебель & $0,3 \pm 0,01$ & $0,3 \pm 0,02$ & $0,3 \pm 0,02$ & $0,3 \pm 0,03$ & $0,2 \pm 0,01$ \\
\hline
\end{tabular}


Таблица 1 (окончание)

\begin{tabular}{|c|c|c|c|c|c|c|}
\hline \multicolumn{2}{|c|}{} & Кызыл - Ярык & Кызыл - Ярык & Кызыл - Ярык & Кызыл - Ярык & Кызыл - Ярык \\
\hline \multirow{3}{*}{$Z n$} & листья & $23 \pm 0,8$ & $24 \pm 0,78$ & $32 \pm 2,1$ & $26 \pm 2,7$ & $20 \pm 0,7$ \\
\cline { 2 - 7 } & плоды & $12 \pm 0,9$ & $13 \pm 0,44$ & $14 \pm 0,9$ & $18 \pm 2,3$ & $8,5 \pm 1,3$ \\
\cline { 2 - 7 } & стебель & $39 \pm 1,4$ & $48 \pm 5,74$ & $52 \pm 2,9$ & $44 \pm 5,5$ & $28 \pm 2,5$ \\
\hline \multirow{3}{*}{$Z r$} & листья & $1,7 \pm 0,1$ & $1,9 \pm 0,08$ & $1,9 \pm 0,1$ & $1,4 \pm 0,1$ & $1,1 \pm 0,1$ \\
\cline { 2 - 7 } & плоды & $0,8 \pm 0,1$ & $1,01 \pm 0,05$ & $0,8 \pm 0,03$ & $0,9 \pm 0,1$ & $0,6 \pm 0,1$ \\
\cline { 2 - 6 } & стебель & $0,7 \pm 0,1$ & $0,9 \pm 0,07$ & $0,8 \pm 0,03$ & $0,6 \pm 0,04$ & $0,42 \pm 0,03$ \\
\hline
\end{tabular}

Листья L. caerulea subsp. altaica по сравнению с другими органами характеризовались более высоким содержанием зольных элементов до 9,5 \%. Повышенную зольность можно обусловить более интенсивным накоплением макроэлементов К до 17,22 г/кг, Са до 20,86г/кг, $\mathrm{Mg}$ до 3,85 г/кг, Р до 4,16 мг/кг и $\mathrm{Si}$ до 1796,5 мг/кг. В листьях наблюдалось и самое высокое содержание микроэлементов: $\mathrm{Sr}, \mathrm{Ni}$, Mo, B, Ga, La и Zr. В плодах отмечалось самое высокое содержание K до 22,301 г/кг, по сравнению с другими органами. В листьях наблюдалось высокое содержание $\mathrm{Ca}, \mathrm{Mg}$ и $\mathrm{Sr}$. А в стебле накапливается больше всего $\mathrm{Mn}$ и $\mathrm{Zn} . \mathrm{Cu}$ распределяется равномерно между листьями, плодами и стеблем, но в микропопуляции Кызыл-Ярык 5 наблюдалось минимальное содержание по сравнению с другими микропопуляциями.

Один из критериев оценки жизненного состояния растительного организма является соотношение в органах растений элементов минерального питания. Поэтому было оценено не только содержание микро- и макроэлементов, но и их соотношение в растениях (табл. 2). В изученной популяции L. caerulea subsp. altaica соотношение $\mathrm{K} / \mathrm{Ca}$ в листьях растений изменялось в пределах $0,5-1,0$, что позволяет отнести этот вид к растениям с кальциотрофным типом минерального обмена (Horak et al., 1971). Необходимым условием для нормального развития растений является соотношение $\mathrm{Fe} / \mathrm{Mn} 1,5-$ 2,5 (Kabata-Pendias, 2011). По нашим данным, минимальной величиной $\mathrm{Fe} / \mathrm{Mn}-0,4$ характеризовались листья L. caerulea subsp. altaica в микропопуляции Кызыл-Ярык 5, что говорит о нарушении поступления Fe в листья растения. Скорее всего, сдвиг в соотношении Fe/Mn в пользу марганца в листьях растений связан с режимом увлажнения на этом участке. Согласно литературным данным повышенные концентрации $\mathrm{Mn}$ часто связывают с увеличением влагообеспеченности места произрастания и кислой реакцией среды. Соотношение $\mathrm{Cu} / \mathrm{Zn}$ является относительно постоянной величиной и связано с процессами ферментосинтеза. Ранее было установлено, что данное соотношение в различных условиях Горного Алтая изменяется в пределах 0,2-0,3 (Боярских и др., 2015), на исследуемом участке соотношение доходит до 0,5 , возможно, это связано с нарушениями физиологических процессов и требует дальнейших исследований.

Таблица 2

Соотношения микро- и макроэлементов в органах L. caerulea subsp. altaica в зависимости от места произрастания

\begin{tabular}{|c|c|c|c|c|c|c|}
\hline \multicolumn{2}{|c|}{} & Кызыл - Ярык & Кызыл - Ярык & Кызыл - Ярык & Кызыл - Ярык & Кызыл - Ярык \\
\hline \multirow{3}{*}{$\mathrm{Cu} / \mathrm{Zn}$} & 1 & 2 & 3 & 4 & 5 \\
\cline { 2 - 7 } & листья & 0,5 & 0,5 & 0,3 & 0,4 & 0,2 \\
\cline { 2 - 7 } & плоды & 1,0 & 1,0 & 1,0 & 0,7 & 0,4 \\
\hline \multirow{3}{*}{$\mathrm{Fe} / \mathrm{Mn}$} & стебель & 0,3 & 0,3 & 0,3 & 0,2 & 0,1 \\
\cline { 2 - 7 } & листья & 1,2 & 1,3 & 1,3 & 0,9 & 0,4 \\
\cline { 2 - 7 } & плоды & 1,2 & 1,2 & 1,5 & 1,1 & 0,8 \\
\hline \multirow{3}{*}{$\mathrm{K} / \mathrm{Ca}$} & стебель & 0,7 & 0,5 & 0,7 & 0,6 & 0,4 \\
\cline { 2 - 7 } & листья & 0,8 & 0,9 & 0,8 & 1,1 & 0,7 \\
\cline { 2 - 7 } & плоды & 5,6 & 6,3 & 6,2 & 1,0 & 1,3 \\
\hline
\end{tabular}




\section{ЛИТЕРАТУРА}

Боярских И. Г., Васильев В. Г., Кукушкина Т. А. Изменение метаболизма Lonicera caerulea в тектонически активной зоне Горного Алтая (Северо-Чуйский хр.) // Раст. мир Азиатской России. 2011. № 2. С. 114-119.

Боярских И. Г., Чанкина О. В., Сысо А. И, Васильев В. Г. Тренды содержания химических элементов в листьях Lonicera caerulea (Caprifoliaceae) в связи с их вторичным метаболизмом в природных популяциях Горного Алтая //Известия РАН. Серия Физическая, 2015. - Т. 79 (1). - С. 106 -110.

Минаева В. Г. Лекарственные растения Сибири. - Новосибирск, 1991. - С. 431.

Стрельцина С. А., Сорокин А. А., Плеханова М. Н., Лобанова Е. В. Состав биологически активных фенольных соединений сортов жимолости в условиях северо-западной зоны плодоводства РФ // Аграрная Россия, 2006. № 6. - C. 67-72.

Agatova A., Nepop R. Dating Strong Prehistoric Earthquakes and Estimating Their Recurrence Interval Applying Radiocarbon Analysis and Dendroseismological Approach - Case Study from SE Altai (Russia) // International Journal of Geohazards and Environment, 2016. - 2(3): 131-149.

Chaovanalikit Arusa, Thompson M. M., Wrolstad R. E. Characterization and quantification of anthocyanins and polyphenolics in Blue Honeysuckle (Lonicera caerulea L.) // J. Agricultural and Food Chem., 2004. - № 52. - P. 848-852.

Jurikova T., Rop O., Mlcek J., Sochor J., Balla S., Szekeres L., Hegedusova A., Hubalek J., Adam V., Kizek R. Phenolic profile of edible honeysuckle berries (genus Lonicera) and their biological effects // Molecules., 2012. - V. 17. - P. 61-79. doi:10.3390/molecules 17010061

Horak O., Kinzel H. Typen des Mineralstoffwechsel bei den hoheren Pflanzen // Osterr. Bot. Z., 1971. - V. 119. - № 4-5. - P. 475-495.

Kabata-Pendias A. Trace Elements in Soils and Plants. - 4th ed. CRC Taylor and Francis Group, 2011. -505 p. 